\title{
Characterization of Intermediate Filaments in PC12 Cells
}

\author{
Linda M. Parysek and Robert D. Goldman \\ Northwestern University Medical School, Department of Cell Biology and Anatomy, Chicago, Illinois 60611
}

A $57 \mathrm{kDa}$ protein is the major polypeptide in intermediate filament (IF)-enriched cytoskeletal preparations obtained from the neuronal cell line PC12 (rat pheochromocytoma). Under the conditions used to assemble IF in vitro from other cultured cell lines, $10 \mathrm{~nm}$ filaments are formed after 2 cycles of disassembly-assembly from PC12 IF-enriched cytoskeletal preparations; the $57 \mathrm{kDa}$ protein is the major component of the final IF pellet.

The $\mathbf{5 7} \mathbf{~ k D a}$ protein is immunologically related to the BHK21 fibroblast $55 \mathrm{kDa}$ protein (vimentin), but a comparison of the peptide maps of PC12 $57 \mathrm{kDa}$ and BHK $55 \mathrm{kDa}$ indicates that they are different proteins. With the use of a polyclonal antiserum to the PC12 $57 \mathrm{kDa}$ protein, immunofluorescence observations of PC12 cells not treated with NGF reveal a juxtanuclear "knot"-like structure. After NGF treatment, the "knots" are less prominent and many IF arrays are seen coursing through the cytoplasm and extending into the neurites. These immunofluorescence observations of the distribution of IF are corroborated by fine-structural analyses.

SDS-PAGE analyses indicate that IF-enriched cytoskeletons isolated from NGF-treated cells have a polypeptide composition similar to that of untreated cells, that is, the $\mathbf{5 7}$ $k D a$ protein remains the major polypeptide. SDS-PAGE and immunoblotting analyses show that untreated and NGFtreated PC12 cells also contain relatively minor amounts of the 68, 150, and $200 \mathrm{kDa}$ neurofilament triplet (NFT) proteins. Under immunofluorescence, only $5 \%$ of untreated PC12 cells are found to contain a juxtanuclear "knot" labeled with NFT antibodies, but with time following NGF treatment, the number of fluorescent cells increases. After about 2 weeks of NGF treatment, all of the PC12 cells appear to contain NFT antlbody-positlve fllamentous structures. As assessed by immunofluorescence, the NFT polypeptides appear to codistribute with the $57 \mathrm{kDa}$ protein in both untreated and NGF-treated PC12 cells.

These data indicate that PC12 cells contain IF composed of a complex set of polypeptides, including a previously unidentified 57 kDa IF protein. While NGF may induce pro-

\footnotetext{
Received May 20, 1986; revised Sept. 15, 1986; accepted Sept. 22, 1986.

We gratefully acknowledge the assistance of Liz Hutton in the preparation of antibodies and for Fig. $4 k$. We thank Dr. L. Gambetti for the generous gift of $68 \mathrm{kDa}$ antiserum. L.M.P. is a fellow of the Les Turner Amyotrophic Lateral Sclerosis (A.L.S.) Foundation. This work was supported by the Les Turner A.L.S. Foundation.

Correspondence should be addressed to Linda M. Parysek, Northwestern University Medical School, Department of Cell Biology and Anatomy, 303 East Chicago Avenue, Chicago, IL 60611.

Copyright (c) 1987 Society for Neuroscience $0270-6474 / 87 / 030781-11 \$ 02.00 / 0$
}

duction of NFT polypeptides, there does not appear to be a "switch" from known mesenchymal IF polypeptide expression to NFT polypeptide expression upon stimulation of PC12 cells with NGF.

In contrast to the other cellular cytoskeletal systems, i.e., microfilaments and microtubules, intermediate filaments (IF) are composed of 1 or more of a large group of related but distinct proteins. The polypeptide composition of cellular IF generally reflects the tissue type from which the cell was obtained or derived (Steinert et al., 1984). The major polypeptides that compose neural IF have been deduced from analyses of the slow component of axonal transport (Hoffman and Lasek, 1975) and from biochemical studies of neural tissue based on the selective fractionation of 68,150 , and $200 \mathrm{kDa}$ proteins into a pellet that contains intermediate-sized filaments (Liem et al., 1978; Schlaepfer and Freeman, 1978). These 3 proteins have also been shown to comprise in vitro assembled IF from mammalian CNS (Liem and Hutchison, 1982; Zackroff et al., 1982). The occurrence of proteins, other than the neurofilament triplet (NFT), that might participate in the formation of neural IF or act as intermediate filament-associated proteins (IFAP) in neuronal cells is a subject for continued investigation.

PC12 (rat pheochromocytoma) cells have been used as a model system for the study of the actions of NGF with regard to neuronal differentiation (for a review, see Guroff, 1985). Among other neuronal characteristics, PC12 cells exhibit neurite outgrowth in response to NGF (Tischler and Greene, 1975), produce catecholamines (Greene and Tischler, 1976), and contain proteins that react with monospecific NFT antibodies (Lee et al., 1982). The PC12 cell line is one of the few continuous cell lines that produce polypeptides that react with NFT antibodies, and it is therefore thought to represent one of the few model systems in which one might study neurofilament biosynthesis and function in a reasonably homogenous cell system.

Although IF from PC12 cells have not been isolated and biochemically characterized, the presence of vimentin antibodyand NFT antibody-reactive proteins has been identified by immunofluorescence and immunoblotting (Lee et al., 1982; Lee and Page, 1984; Lee, 1985). Using an ELISA assay, it has been shown that PC12 cells exposed to NGF contain an increased amount of vimentin and NFT proteins and that the ratio of vimentin antibody-reactive material to $68 \mathrm{kDa}$ (NFT protein) antibody-reactive material decreases from 3.0 to 1.5 as compared to untreated cells. Further, the $68 \mathrm{kDa}$ protein and vimentin antibody-reactive protein were localized in the same juxtanuclear "ball"-like configurations, while the 150 and 200 $\mathrm{kDa}$ NFT antibody-reactive proteins were diffusely distributed, with perinuclear stippling and weakly fluorescent "balls" (Lee 
and Page, 1984). A recent study indicated that the NFT 200 $\mathrm{kDa}$ protein could not be detected in $\mathrm{PC} 12$ cells by immunoblotting, leading to the conclusion that neurofilaments in $\mathrm{PC} 12$ cells may be abnormal, due to a deficiency in the expression of or alteration in the immunoreactivity of PC12 $200 \mathrm{kDa}$ protein (Lee, 1985).

The difficulties inherent in interpreting exclusively immunologic data prompted us to more precisely characterize the components of the IF system in $\mathrm{PC} 12$ cells by preparing IFenriched cytoskeletons so that the relative amounts of purported vimentin-like and NFT proteins might be directly assessed. The procedure employed here has been used successfully to characterize complex IF systems (including their associated proteins) in other cell types (Starger et al., 1978; Aynardi et al., 1984; Jones and Goldman, 1985). We find that a $57 \mathrm{kDa}$ protein, not vimentin, is the major component of PC12 IF and that NFT polypeptides appear to be minor components of the total IFenriched cytoskeletal preparation. In addition, the morphologic data presented here help explore the nature of the reported "ball"-like configurations (Lee et al., 1982) with increased resolution, using coordinated fluorescence and electron microscopy.

\section{Materials and Methods}

Cell culture. PC1 2 cells were obtained from G. Landreth (Medical University of South Carolina) and maintained in Dulbecco's minimal essential medium with high glucose, $10 \%$ defined calf serum, $5 \%$ horse serum, and penicillin-streptomycin (Feinstein et al., 1985). $\beta$-NGF was obtained from Hyclone (Logan, UT) and used at $50 \mathrm{ng} / \mathrm{ml}$ culture medium. For some experiments, an estimate of the number of cells present in the cultures was obtained by counting the number of cells in phase micrographs of a $0.33 \mathrm{~cm}^{2}$ area of the culture dish. The phase images were recorded from random areas of the culture dish, and cell counts were averaged over several determinations.

Antibodies. Monoclonal antibodies used in this study were prepared using standard fusion techniques with SP2/0 myeloma cells and spleen cells from mice that had been injected 6 weeks previously with rat neurofilament proteins isolatcd according to Zackroff et al. (1982). Each clone producing a desired antibody was recloned twice, either by the soft agar or limiting dilution method. Culture supernatants were used without dilution for the immunofluorescence and immunoblotting experiments.

Polyclonal antisera directed against the 150 and $200 \mathrm{kDa}$ NFT subunits were each prepared by injection of gel-excised, electrophoretically purified 150 and $200 \mathrm{kDa}$ proteins into rabbits (Granger and Lazarides, 1980). Sera from the first bleed of the $200 \mathrm{kDa}$ rabbit and the third bleed of the $150 \mathrm{kDa}$ rabbit were used in all experiments described in this report. The same method was used to prepare an antiserum to the PC12 $57 \mathrm{kDa}$ protein. Serum from the first bleed was used here. For immunofluorescence observations, the polyclonal $150 \mathrm{kDa}$ antiserum was affinity-purified from diazophenylthioether (DPT) paper blots of rat brain and PC12 cell IF preparations (Olmsted, 1981).

A rabbit antiserum to the $68 \mathrm{kDa}$ subunit was the generous gift of Dr. L. Gambetti (Autilio-Gambetti et al., 1981).

Immunofluorescence. Cells were grown on untreated or $0.1 \%$ poly-Llysine-coated (when NGF was to be added) $22 \mathrm{~mm}^{2}$ coverslips. The coverslips were rinsed in PBSa $(140 \mathrm{~mm} \mathrm{NaCl}, 3 \mathrm{~mm} \mathrm{KCl}, 8 \mathrm{~mm}$ $\left.\mathrm{Na}_{2} \mathrm{HPO}_{4} \cdot 7 \mathrm{H}_{2} \mathrm{O}, 1.5 \mathrm{mM} \mathrm{KH} \mathrm{PO}_{4} ; \mathrm{pH} 7.2\right)$ and drained before being plunged into $2 \%$ formaldehyde-methanol at $-15^{\circ} \mathrm{C}$. After $5 \mathrm{~min}$, the coverslips were transferred to PBSa at room temperature; then culture supernatants or polyclonal antisera diluted in $10 \%$ normal goat serum were applied. Goat anti-mouse IgG-rhodamine and goat anti-rabbit IgG-fluorescein (Kirkegaard and Perry, Gaithersburg, MD) were preabsorbed with acetone-precipitated whole PC12 cells (Yumura et al., 1984) to reduce nonspecific fluorescence prior to their use as secondary probes for immunofluorescence. For most immunostaining procedures, cells were first flattened under agarose (Fukui et al., 1986, 1987), then immediately fixed in $2 \%$ formaldehyde-methanol at $-15^{\circ} \mathrm{C}$ for $5 \mathrm{~min}$. Agarose pieces were gently removed in PBSa after fixation and culture supernatants or polyclonal antisera were applied as described above. The distribution of certain antibody-labeling patterns among PC12 cells was identified by counting the number of labeled cells per 100 cells. Five hundred cells per slide were counted in 2 or more different preparations.

IF-enriched cytoskeletal preparations. Native IF-enriched cytoskeletal networks were isolated from BHK-21 cells as previously described (Jones and Goldman, 1985). To isolate PC12 cell IF-enriched cytoskeletons, the identical procedure was used. For experiments in which IFenriched polypeptides from cells cultured in the absence or presence of NGF were to be compared, equal numbers of cells were plated into 100 $\mathrm{mm}$ dishes, NGF and media werc rcplaced every $48 \mathrm{hr}$, and the cells were cultured for $7 \mathrm{~d}$. IF preparations were made from equal numbers of dishes and solubilized in equal amounts of Laemmli (1970) sample buffer for analysis. Isolation of neural IF polypeptides from rat spinal cord was carried out as described by Lee (1985); however, a DNAase digestion step was added to the final spinal cord IF pellet as in the cultured cell IF-enrichment procedure (Jones and Goldman, 1985).

Some IF-enriched cytoskeletal preparations were subjected to 2 cycles of disassembly-assembly. Native IF pellets were solubilized by stirring in a urea-containing disassembly buffer (Goldman et al., 1986) at room temperature for $3 \mathrm{hr}$. The protein concentration of this solution was $0.8-1.0 \mathrm{mg} / \mathrm{ml}$, as assessed by the Bradford method (1976). Ureainsoluble material was removed by centrifugation at $250,000 \times \mathrm{g}$ for 1 $\mathrm{hr}$ at $15^{\circ} \mathrm{C}$, and the resulting supernatant dialyzed against PBSa with $0.2 \mathrm{~mm}$ phenylmethylsulfonyl fluoride (PMSF) and $0.2 \% \beta$-mercaptoethanol overnight at room temperature. The dialyzed supernatant was centrifuged at $250,000 \times g$ for $1 \mathrm{hr}$ at $15^{\circ} \mathrm{C}$ and the resulting IF pellet solubilized in urea-disassembly buffer to begin the second cycle of IF disassembly-reassembly. The pellet that was collected after the second PBSa dialysis step is called the "twice-cycled IF pellet"; it was analyzed by SDS-PAGE and by electron microscopy.

Electrophoresis and immunoblotting. Seven percent SDS-polyacrylamide gels were used throughout this study to analyze IF-enriched preparations (Laemmli, 1970). Silver-stained gels (Oakley et al., 1980) of peptide maps were $15 \%$ acrylamide (Cleveland et al., 1977). To ensure good separation of 54 and $55 \mathrm{kDa}$ BHK IF subunits for peptide mapping, gels were allowed to run $\sim 30$ min past the time when the tracking dye ran into the lower buffer chamber. The migration of unknown polypeptides was compared with that of myosin $(200,000), \beta$-galactosidase $(116,000)$, phosphorylase B $(92,500)$, BSA $(66,000)$, and ovalbumin $(45,000)$. Molecular weights were estimated from a semilog plot of denatured molecular weight relative to distance migrated. To determine the relative amounts of $57 \mathrm{kDa}$ protein present in the gel lanes to be compared, gels were scanned by a densitometer (E-C Corp.) and peak areas and height were quantitated by a plotting-reporting integrator (Hewlett-Packard).

For Western blotting, gels were transferred to $0.45 \mu \mathrm{m}$ pore size nitrocellulose paper, according to the method of Towbin et al. (1979). The paper was blocked with GTS (10 mM Tris- $7.5,0.9 \% \mathrm{NaCl}, 0.25 \%$ gelatin) and incubated for 10-14 hr with antibodies diluted with the same buffer. Antibody binding was detected with 4-chloro-L-naphthol.

Electron microscopy. Thirty-five millimeter plastic culture dishes containing coverslips of PC12 cells were washed once with PBSa, then fixed for $30 \mathrm{~min}$ with $2.0 \%$ glutaraldehyde in PBS (PBSa plus $0.5 \mathrm{mM} \mathrm{MgCl}_{2}$. $\mathrm{H}_{2} \mathrm{O}, 0.9 \mathrm{mM} \mathrm{CaCl}_{2} \cdot \mathrm{H}_{2} \mathrm{O}$ ). After washing, cells were treated with $1.5 \%$ tannic acid in $0.05 \mathrm{~mm}$ cacodylate for $1 \mathrm{~min}$, then $0.15 \%$ tannic acid for $30 \mathrm{~min}$. Postfixation in $0.5 \% \mathrm{OsO}_{4}$ in $0.05 \mathrm{M}$ cacodylate, $\mathrm{pH} 7.2$, for $15 \mathrm{~min}$ on ice was followed by washing and immersion in $2 \%$ uranyl acetate for $75 \mathrm{~min}$. The fixed cells were flat-embedded in Epon/Araldite and, following polymerization, thin sections were prepared and stained with uranyl acetate and lead citrate. Pellets of IF-enriched cytoskeletal preparations, obtained after the final PBSa wash, were processed for electron microscopy as are whole cells, except that en bloc uranyl acetate staining was omitted.Twice-cycled IF on Formvar- and carbon-coated grids were negative-stained with $3.0 \%$ uranyl acetate. All observations were made on a Jeol $200 \mathrm{CX}$ operated at $80 \mathrm{kV}$.

\section{Results}

\section{Composition of PC12 IF-enriched cytoskeletons}

The gel-electrophoretic profiles of proteins comprising IF-enriched cytoskeletal preparations from $\mathrm{PC} 12$ cells grown without NGF show several bands, the most prominent of which is a 57 $\mathrm{kDa}$ polypeptide (Fig. 1a, lane 2). This polypeptide did not comigrate with either of the structural subunits $(54$ or $55 \mathrm{kDa}$; desmin and vimentin, respectively) of BHK-21 IF (Fig. 1 $a$, lane 

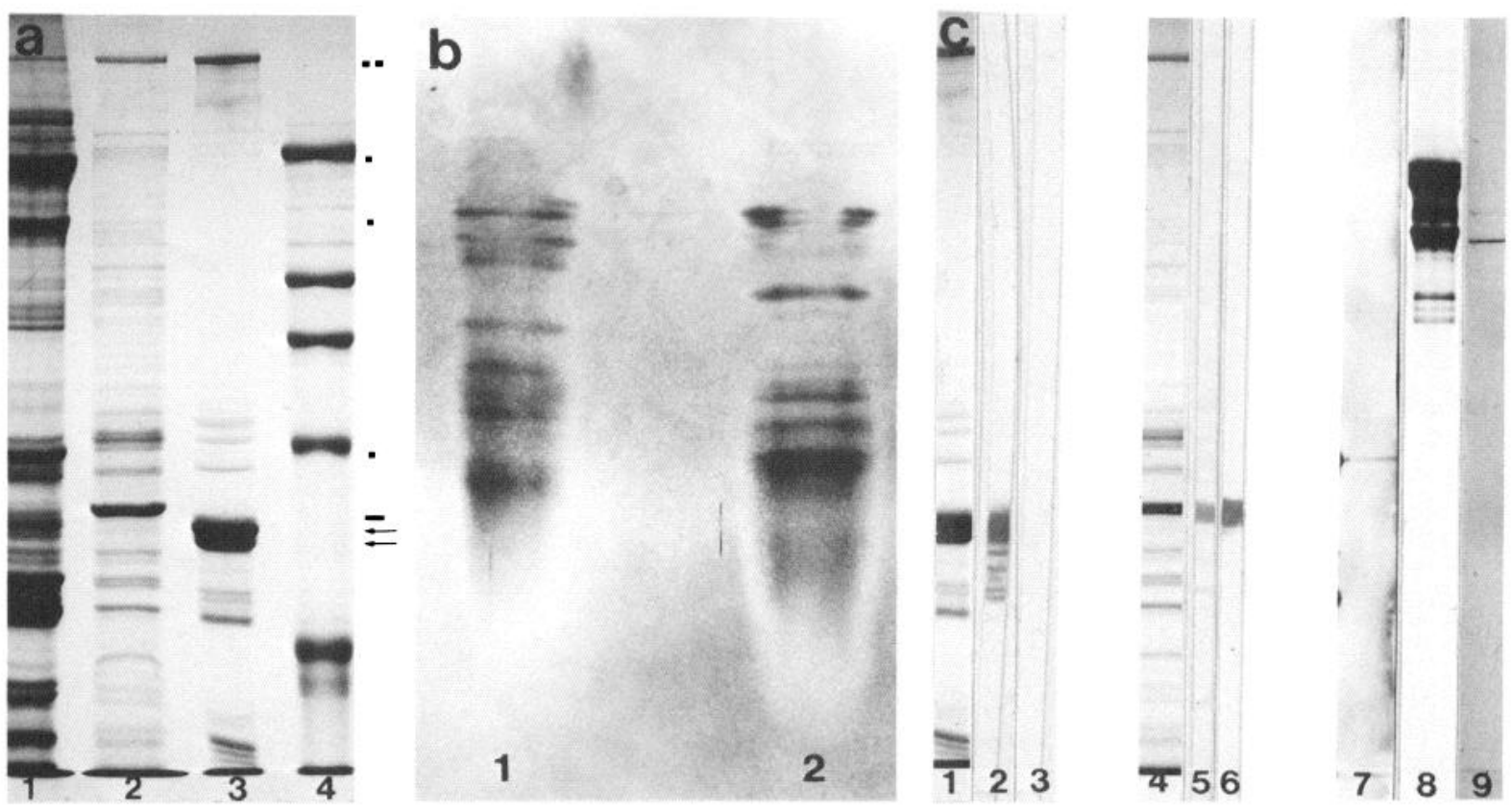

Figure 1. Composition of the PC12 IF-enriched cytoskeleton. $a$, Coomassie blue-stained gel of a crude preparation of rat spinal cord neurofilaments (lane 1), a PC12 (lane 2) and BHK (lane 3) IF-enriched cytoskeletal preparation and molecular weight standards (lane 4). Major bands in lane 4 are, from the top, $200 \mathrm{kDa}, 116 \mathrm{kDa}, 97.5 \mathrm{kDa}, 66 \mathrm{kDa}$, and $45 \mathrm{kDa}$. Dots indicate, from top, migration of 200, 150 , and $68 \mathrm{kDa}$ NFT proteins. The major component of the PC12 IF-enriched cytoskeletal preparation is a $57 \mathrm{kDa}$ protein (dash) that does not comigrate with either of the BHK $54-55 \mathrm{kDa}$ (arrows) IF subunits. Double dots, $300 \mathrm{kDa}$. b. Peptide maps of BHK $55 \mathrm{kDa}$ (vimentin; lane 1) and PC12 $57 \mathrm{kDa}$ (lane 2) proteins. The peptide map of the PC12 $57 \mathrm{kDa}$ protein is unlike that of vimentin, $c$, Lane 1, Coomassie blue-stained gel of a BHK IF preparation. Lanes 2 and 3, Immunoblots of the BHK IF preparation labeled with a BHK $55 \mathrm{kDa}$ (vimentin) antibody (lane 2) and a polyclonal $57 \mathrm{kDa}$ ab (lane 3). Coomassie blue-stained gel of a PC12 IF preparation (lane 3). Lanes 5-7, 9, Immunoblots of a PC12 IF preparation labeled with a BHK 55 kDa (vimentin) ab (lane 5), a polyclonal $57 \mathrm{kDa}$ ab (lane 6), a polyclonal $68 \mathrm{kDa}$ ab (lane 7), and a monoclonal ab to neural 150 and $200 \mathrm{kDa}$ proteins (lane 9). Lane 8, Immunoblot of rat spinal cord IF labeled with a monoclonal ab to 150 and $200 \mathrm{kDa}$ proteins. A polyclonal ab directed against the BHK $55 \mathrm{kDa}$ protein labels the major structural subunits of both PC12 and BHK IF preparations. A polyclonal ab prepared against the PC12 $57 \mathrm{kDa}$ protein, however, does not label the BHK $55 \mathrm{kDa}$ protein. These data, along with the SDS-PAGE data in this figure, indicate that although PC12 $57 \mathrm{kDa}$ and BHK $55 \mathrm{kDa}$ proteins may share some immunologic relationship, they are distinct proteins. The 68 , 150, and presumptive dephosphorylated $200 \mathrm{kDa}$ NFT components also are detected in PC12 IF-enriched cytoskeletal preparations.

3). In addition, silver-stained gels of their proteolytic fragments showed that the PC12 $57 \mathrm{kDa}$ protein and BHK $55 \mathrm{kDa}$ protein (vimentin) had very few proteolytically derived peptides in common (Fig. $1 b$ ). Comparison of the $57 \mathrm{kDa}$ peptide map to maps of vimentin from other fibroblast cell lines yielded identical results (not shown).

A second, prominent component of the $\mathrm{PC} 12$ cytoskeletal preparation was a polypeptide of $300 \mathrm{kDa}$ that comigrated and shared immunoidentity with a $300 \mathrm{kDa}$ IFAP (not shown) that has been described previously (Lieska et al., 1985; Yang et al., 1985) (Fig. 1 $a$, lanes 2 and 3). In addition, the BHK $300 \mathrm{kDa}$ IFAP and PC12 $300 \mathrm{kDa}$ proteins exhibited identical peptide maps (not shown). Note that a protein was also present in the rat spinal cord IF preparation that comigrated with $\mathrm{PC} 12$ and the BHK $300 \mathrm{kDa}$ protein (Fig. 1a).

Despite their dissimilar peptide compositions, the BHK 55 $\mathrm{kDa}$ and PC12 $57 \mathrm{kDa}$ proteins were both recognized by 3 polyclonal antisera to the $\mathrm{BHK}$ fibroblast-derived $55 \mathrm{kDa}$ protein (vimentin). The immunoblotting analysis of one of these antisera is shown in Figure 1c, lanes 2 and 5. A polyclonal antiserum to the $\mathrm{PC} 1257 \mathrm{kDa}$ protein (Fig. 1c, lane 6), however, did not label BHK $55 \mathrm{kDa}$ protein on immunoblots (lane 3).

Careful comparisons of the rat spinal cord and PC12 IFs indicated that proteins that might correspond to the 68,150 , and $200 \mathrm{kDa}$ NFT proteins in rat spinal cord were not prominent in Coomassie blue-stained gels of PC12 IF-enriched cytoskeletons (Fig. 1a, compare lanes 1 and 2). NFT antibody-reactive proteins, however, could be detected on immunoblots of PC12 cell IF preparations. A polyclonal antiserum directed against rat $68 \mathrm{kDa}$ protein detected a single band in PC12 IF preparations (Fig. 1c, lane 7) that comigrated with the rat $68 \mathrm{kDa}$ protein (not shown). A monoclonal antibody that recognized rat spinal cord 150 and $200 \mathrm{kDa}$ proteins (Fig. $1 c$, lane 8 ) showed positive immunoreactivity with bands in PC12 IF preparations of molecular weights identical to rat $150 \mathrm{kDa}$ and presumptive dephosphorylated $200 \mathrm{kDa}$ proteins (Fig. 1c, lane 9) (see Julien and Mushynski, 1983). This monoclonal antibody and a polyclonal antiserum to rat $150 \mathrm{kDa}$ protein both detected a triplet of tightly spaced bands in PC12 IF preparations that comigrated with rat $150 \mathrm{kDa}$ protein (see inset, Fig. $3 d$ ), as well as with a set of bands between $\sim 100$ and $120 \mathrm{kDa}$. These bands, which migrated faster than the $150 \mathrm{kDa}$ protein, may be degradation fragments or otherwise related to the $150 \mathrm{kDa}$ protein, since they were recognized by other antibodies to the $150 \mathrm{kDa}$ NFT protein (not shown).

Thus, it appears that IF-enriched cytoskeletal preparations of non-NGF-treated PC12 cells contained a complex set of polypeptides, including major proteins of $57 \mathrm{kDa}$, which appeared to be different from fibroblast vimentin, and of $300 \mathrm{kDa}$, which were similar to the $300 \mathrm{kDa}$ IFAP described previously. Relatively small amounts of NFT protein also were present, along with numerous minor unknown species of polypeptides.

Electron-microscopic examination of the PC12 IF-enriched cytoskeletal preparations revealed the presence of masses of IF 

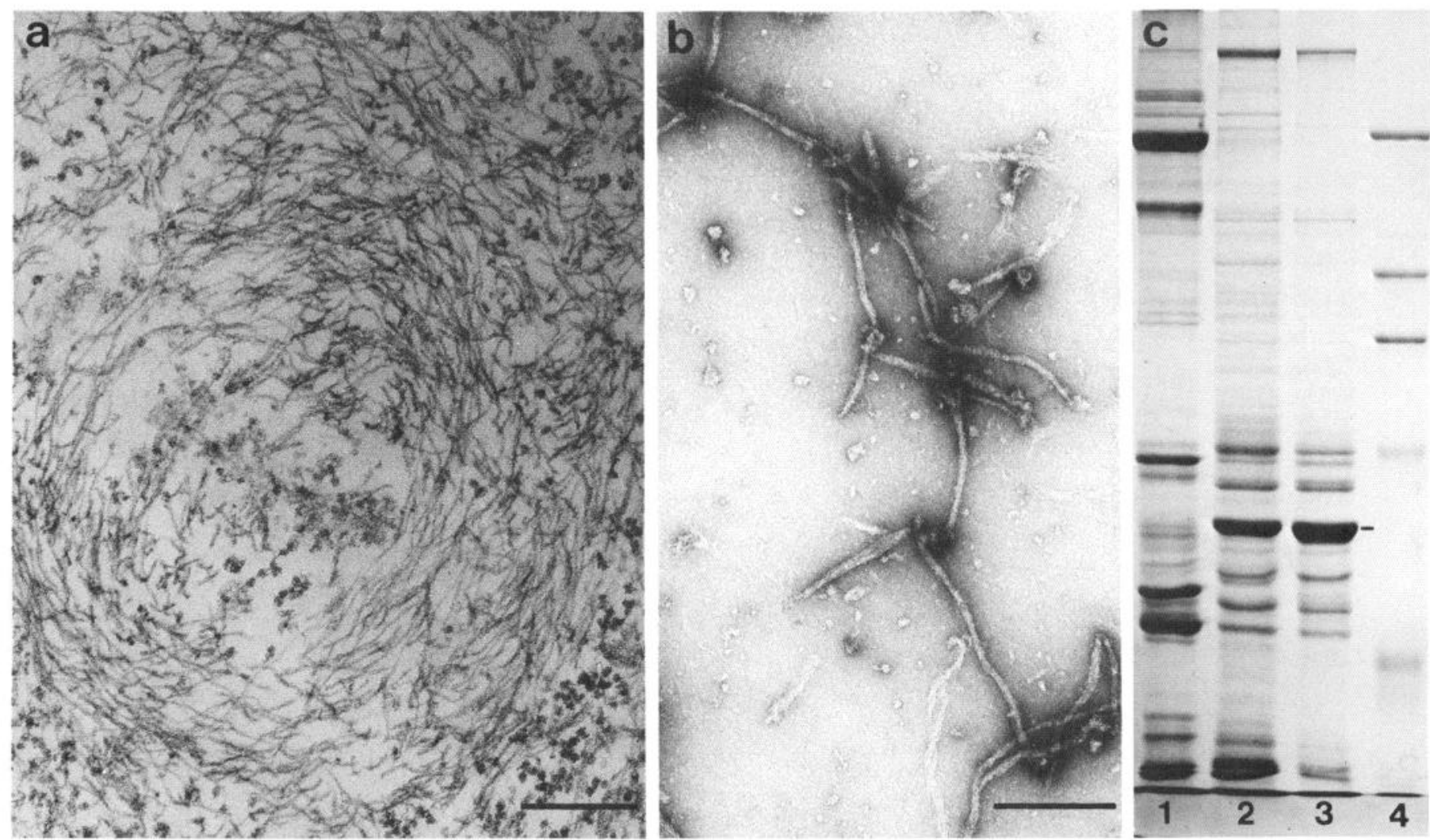

Figure 2. The $57 \mathrm{kDa}$ protein is the major component of PC12 IF. $a$, Thin-sections of the PC12 cell IF-enriched cytoskeletal preparation show that IF are the major structural component. $b$, Electron microscopy of a pellet obtained after 2 cycles of in vitro disassembly-assembly of the native IF pellet illustrates filaments of $\sim 10 \mathrm{~nm}$ in diameter by negative staining. $c$, SDS-PAGE analyses indicate the subunits of PC12 IF after 2 cycles of assembly (lane 3). The $57 \mathrm{kDa}$ polypeptide (dash) is the major protein in both the native (lane 2) and twice-cycled (lane 3) IF preparation. Rat spinal cord neural IF (lane 1) and molecular weight markers (lane 4) are shown for reference. Bars, $0.25 \mu \mathrm{m}$.

(10 nm diameter) (Fig. 2a). Other components seen among the IF were centrioles and nuclear remnants (not shown).

To ascertain whether the $57 \mathrm{kDa}$ protein was a component of IF and not of any other organelle that fortuitously coisolated with the IF-enriched cytoskeleton, we attempted in vitro assembly of IF from the PC12 cytoskeletal pellet. Negative-stain images of the reassembled pellet obtained after 2 cycles of disassembly-assembly revealed that the major components were filaments of $\sim 10 \mathrm{~nm}$ in diameter, with varying lengths (Fig. $2 b$ ). SDS-PAGE analyses of these same preparations indicated that numerous minor bands in the gel and the $300 \mathrm{kDa}$ protein appeared to be diminished (Fig. 2c, lane 3) compared to the native IF-enriched cytoskeletal preparation (Fig. 2c, lane 2). The $57 \mathrm{kDa}$ protein, however, remained the major polypeptide in the cycled preparation. These data on the native IF-enriched cytoskeletal preparation and the twice-cycled IF pellet strongly suggest that the $57 \mathrm{kDa}$ protein is the major component of $\mathrm{PC} 12$ cell IF.

\section{Changes in IF-related polypeptides after NGF treatment}

To assess the effect of NGF on IF polypeptide composition, IFenriched cytoskeletal preparations were made from equal numbers of dishes of PC12 cells grown either in the presence or absence of NGF, and compared. After $7 \mathrm{~d}$ of NGF treatment, approximately one-third fewer cells were present per unit area of the culture dish than appeared in the untreated cultures. The NGF-treated cells showed extensive neurite formation and exhibited hypertrophy (Fig. 3a), while the control cells remained round. SDS-PAGE results indicated that despite a decrease in the total number of cells in NGF-treated cultures, an increased amount of IF-enriched cytoskeletal material was derived from these cultures (Fig. $3 b$ ). As an indicator of possible changes in NFT polypeptides, a polyclonal $150 \mathrm{kDa}$ antiserum was used to immunoblot gels similar to those in Figure $3 a$. This blot (Fig. $3 c$ ) indicated that, in the NGF-treated cell lane, PC12 $150 \mathrm{kDa}$ protein showed an increase in blot-reaction intensity, compared to the preparation of untreated $\mathrm{PC} 12$ cell IF.

As a measure of the specificity of the effect of NGF, it is important to determine whether or not the NFT polypeptides increase in comparison to the other IF proteins. When gel samples from an experiment like that described above were loaded onto gels such that the $57 \mathrm{kDa}$ protein was approximately equal in each lane, an identifiable increase in the number of NFT proteins was not readily apparent (Fig. $3 d$ ). Immunoblotting analyses of a similar gel, however, indicated that the relative intensity of the $150 \mathrm{kDa}$ antibody reaction was greater after 7 $\mathrm{d}$ of NGF treatment than in the untreated culture (Fig. $3 e$ ). These qualitative data suggest that, in response to NGF, there is a slight, immunologically detectable increase in NFT relative to the $57 \mathrm{kDa}$ protein in the PC12 cell IF-enriched cytoskeletal preparations.

\section{Immunofluorescence}

The pattern of IF in PC12 cells is not easily discernible by immunofluorescence because the cells are very small and round. The antiserum to the $57 \mathrm{kDa}$ protein labeled a bright area of 
fluorescence next to the nucleus (Fig. 4a). To ascertain the nature of the bright area labeled by the $57 \mathrm{kDa}$ antiserum, we gently flattened the cells immediately prior to fixation. This technique has been used successfully to study the cytoskeleton in Dictyostelium, including its response to cyclic AMP (Yumura and Fukui, 1985; Fukui et al., 1987), and in cultured cells (Fukui et al., 1986). All of the fluorescence images in subsequent figures in this report were obtained after flattening. This technique significantly improved the fluorescence image and enabled us to determine that the "bright area" seen in unflattened cells was actually a distinct tangle of filamentous elements (Fig. $4 b$ ). The knot was juxtanuclear and, in most cases, several filamentous structures extended from the knot on either side of the nucleus.

In order to detect expression of the NFT proteins in these untreated cells, a monoclonal $150 \mathrm{kDa}$ antibody was used in double-label experiments with the antiserum directed against the PC12 $57 \mathrm{kDa}$ protein. Only a small percentage $(5 \%)$ of untreated PC12 cells labeled with $150 \mathrm{kDa}$ antibody contained a large, juxtanuclear array of IF like that seen with $57 \mathrm{kDa}$ antiserum (Fig. 4, b, c). The filamentous labeling patterns of the 57 and $150 \mathrm{kDa}$ antibodies appeared to be coincident. In addition, some clusters of cells in the culture $(32 \%$ of the total number of cells) contained tiny foci of $150 \mathrm{kDa}$ fluorescence that correlated with the brightest area of $57 \mathrm{kDa}$ fluorescence (see Fig. 4c). The percentage of cells that contained filamentous structures labeled with $150 \mathrm{kDa}$ antiserum was identical to the percentage of cells labeled with the $68 \mathrm{kDa}$ polyclonal antiserum. Double-labeling with these 2 antibodies indicated that the same cells reacted with each antibody, and the labeling patterns of the filamentous structures appeared to be identical (Fig. 4,e,f). These data show that the majority of untreated PC12 cells do not express filamentous arrays containing immunodetectable NFT polypeptides, but, in those that do, the $57 \mathrm{kDa}$ and NFT proteins appear to be codistributed.

A monoclonal antibody that reacted with both the rat 150 and $200 \mathrm{kDa}$ NFT proteins labeled distinct dots in the cytoplasm in $16 \%$ of the cells (Fig. $4 g$ ), and these dots were not detected by a double label with either a 57 or $68 \mathrm{kDa}$ antiserum (not shown). The dots could be found both in cells that had a filamentous knot and in those with no filamentous pattern by immunofluorescence with this antibody. These dots were detectable with other antibodies to the $150 \mathrm{kDa}$ protein, but were best illustrated with the 150 and $200 \mathrm{kDa}$ antibody. They did not label with $200 \mathrm{kDa}$ antiserum (not shown).

Even though the BHK $55 \mathrm{kDa}$ (vimentin) antiserum labeled the PC12 $57 \mathrm{kDa}$ protein in immunoblotting tests (see Fig. 1c), the immunofluorescence pattern of vimentin was different from that obtained with antibodies directed against the $57 \mathrm{kDa}$ protein. Whereas $99 \%$ of the cells labeled with $57 \mathrm{kDa}$ antiserum, only $20 \%$ of PC 12 cells exhibited positive fluorescence with antivimentin. For the most part, the fluorescence patterns were restricted to a small, round juxtanuclear region and, in rare cases, a filamentous labeling pattern could be discerned (see Fig. $4 j$ ). Double-label studies showed that this small, round area coincided with the center of the knot labeled with the $57 \mathrm{kDa}$ antiserum and that any anti-vimentin-labeled filaments were different from those labeled with the $57 \mathrm{kDa}$ antiserum (Figs. 4, $i, j)$. The vimentin antibody labeled a typical array of IF in BHK cells (Fig. 4k). This immunofluorescence data further indicates that the $57 \mathrm{kDa}$ protein, not the typical mesenchymal type of IF protein (vimentin), is the major component of the IF network in $\mathrm{PC} 12$ cells.

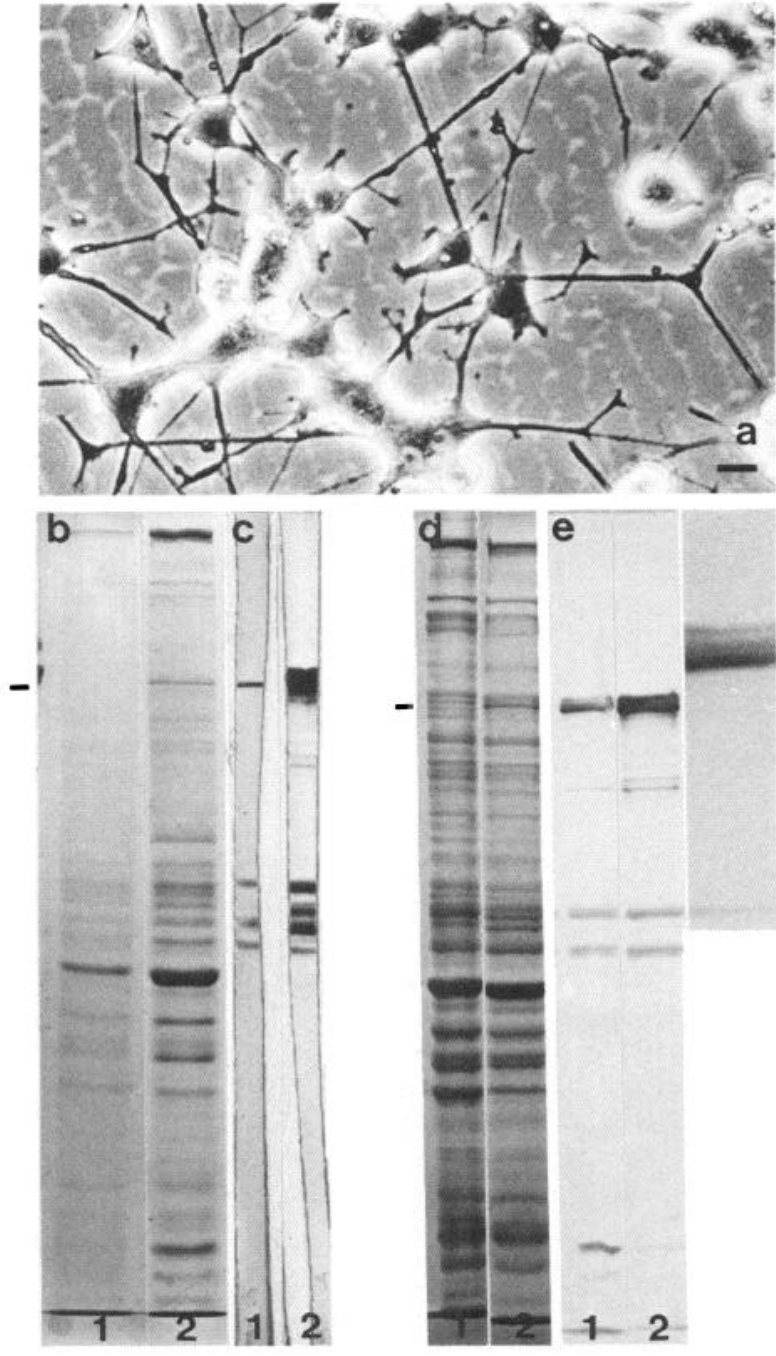

Figure 3. Comparison of the composition of PC12 IF-enriched cytoskeletal preparations of untreated and NGF-treated cells. $a$, Phase image of PC12 cells after $7 \mathrm{~d}$ of NGF treatment. $b, d$, Coomassie bluestained gels of IF preparations and $(c, e)$ immunoblots of the same preparations as in $b$ and $d$ of untreated (lane I) and NGF-treated (lane 2 ) cells. When equal volumes of sample from an equal number of culture dishes are compared, the NGF-treated sample appears to contain greater amounts of IF protein $(b)$, including the $150 \mathrm{kDa}$ NFT protein $(c)$. If the samples are compared when amounts of $57 \mathrm{kDa}$ protein in each gel lane are approximately equal for both cultures $(d)$, there appears to be a slight immunodetectable $(e)$ increase in the $150 \mathrm{kDa}$ protein, compared to the major IF subunit in PC1 2 cells. Inset is a magnification of $e$, lane $I$, showing that the $150 \mathrm{kDa}$ ab reacts with a closely spaced triplet of polypeptides in PC12 cells. Dash indicates $150 \mathrm{kDa}$. Bar, $10 \mu \mathrm{m}$.

After NGF treatment, the cells extended neurites, became hypertrophic, and flattened. Accordingly, their IF patterns changed from those observed in untreated cells. Many cells retained a bright IF-enriched knot, but many filamentous structures radiated from the knot and became dispersed throughout the cytoplasm of the cell (Fig. 5, $a, b$ ), which suggests the presence of increased numbers of IF. Whereas only $5 \%$ of untreated cells reacted with NFT protein antibodies in untreated cells, after about 2 weeks of NGF treatment, all the cells in the culture contained NFT protein, as detected by indirect immunofluorescence. The filamentous structures extended into the neurites and often ended in a tortuous knot at the tip of the neurite (Fig. 

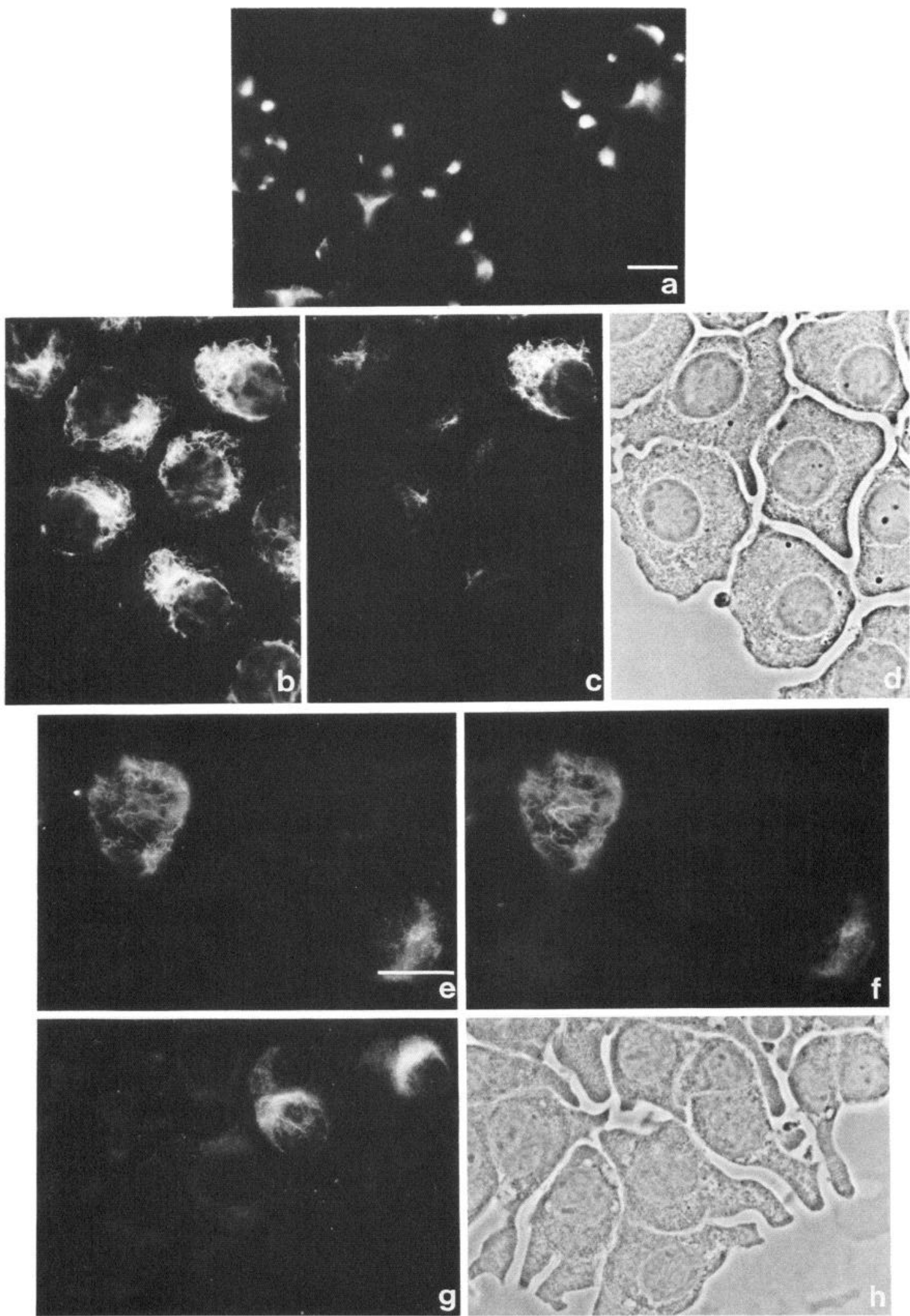

Figure 4. Immunofluorescence of untreated PC12 cells. $a$, Cells labeled with $57 \mathrm{kDa}$ ab. Images $b-j$ are obtained after flattening PC12 cells under agarose. Cells double-labeled with a $57 \mathrm{kDa}$ ab $(b)$ and a $150 \mathrm{kDa}$ ab $(c)$, and corresponding phase image $(d)$. Cells double-labeled with $68 \mathrm{kDa}(e)$ and $150 \mathrm{kDa}(f)$ ab. Cells labeled with an ab to the 150 and $200 \mathrm{kDa}$ NFT proteins $(g)$ and corresponding phase image $(h)$. Cells double-labeled with $57 \mathrm{kDa}(i)$ and vimentin $(j)$ abs. BHK cell labeled with vimentin abs. The "ball" of $57 \mathrm{kDa}$ fluorescence in $a$ can be resolved by gently flattening the cells $(b) . b-f$. Indications that only a subset of the PC1 2 cells labeled with $57 \mathrm{kDa}$ ab can be labeled with NFT protein abs, but that in those cells that are labeled, the 57,68 , and $150 \mathrm{kDA}$ labeling patterns appear to be coincident. $g$, Both a filamentous and nonfilamentous (dotted) 
$5 c$ ). The labeling patterns of the $57 \mathrm{kDa}$ protein and NFT proteins still appeared to be coincident, as they did in the untreated cells (not shown).

\section{Electron microscopy}

Untreated and NGF-treated PC12 cells were prepared for electron microscopy to determine the nature of the "knot" seen by immunofluorescence and to examine any IF relationship to other cellular components that would not be detected by immunofluorescence.

In thin cross sections, untreated PC12 cells appeared very rounded. The greatest number of IF were found in the area of the centriole and Golgi apparatus (Fig. 6a). As seen in cross section, the centriole and Golgi complex were situated most often on the side of the nucleus in the lower, rather than the upper half of the cell, using the substrate as a reference point for the lower half. In addition, IF were seen adjacent to the nucleus (Fig. $6 b$ ). These accumulations of IF probably accounted for the juxtanuclear concentration of IF, seen as a knotlike structure by immunofluorescence.

After NGF treatment, individual and parallel arrays of IF were seen with much greater frequency throughout the cytoplasm than in untreated cells. The concentration of IF in the centriole and Golgi area appeared morphologically similar to that found in untreated cell cultures. In addition, we observed IF in neurites, where they were most often located in the central core region (Fig. 6c). Microtubules were prominent structural components of the neurite (Fig. $6 c$ ).

\section{Discussion}

PC12 cells have been proposed as a model for the study of neuronal differentiation (see Guroff, 1985) and neurofilament synthesis (Lee and Page, 1984). They have been shown to contain proteins that are immunoreactive with vimentin antibody and with NFT antibodies (Lee et al., 1982; Lee and Page, 1984). We have observed, however, that the major polypeptide in the IF-enriched cytoskeleton of PC12 cells is a $57 \mathrm{kDa}$ protein that is different from vimentin or any known neurofilament protein. Although the migration of the PC1 $257 \mathrm{kDa}$ protein is similar to vimentin on SDS-PAGE, the relationship of PC12 $57 \mathrm{kDa}$ protein to fibroblast vimentin appears to be primarily immunological. It is not surprising that the vimentin antiserum seems to react with the PC12 $57 \mathrm{kDa}$ protein on immunoblots, as all IF have conserved structural domains (review in Steinert et al., 1984). The term "vimentin" refers to a major structural subunit protein of $57 \mathrm{kDa}$ isolated from fibroblasts (Franke et al., 1978). The peptide map of the PC12 $57 \mathrm{kDa}$ protein is different from that of vimentin, and the PC12 labeling pattern using $57 \mathrm{kDa}$ antiserum is unlike that seen with vimentin antiserum. We have further distinguished the $57 \mathrm{kDa}$ protein from vimentin by comparing the labeling pattern of each antiserum on frozen sections of the CNS and peripheral nervous system and find that, in contrast to vimentin, the $57 \mathrm{kDa}$ protein is found in neuronal elements (unpublished observations). Because we have demonstrated that PC12 $57 \mathrm{kDa}$ protein is not similar in composition to fibroblast vimentin, we will refer to the PC12 $57 \mathrm{kDa}$
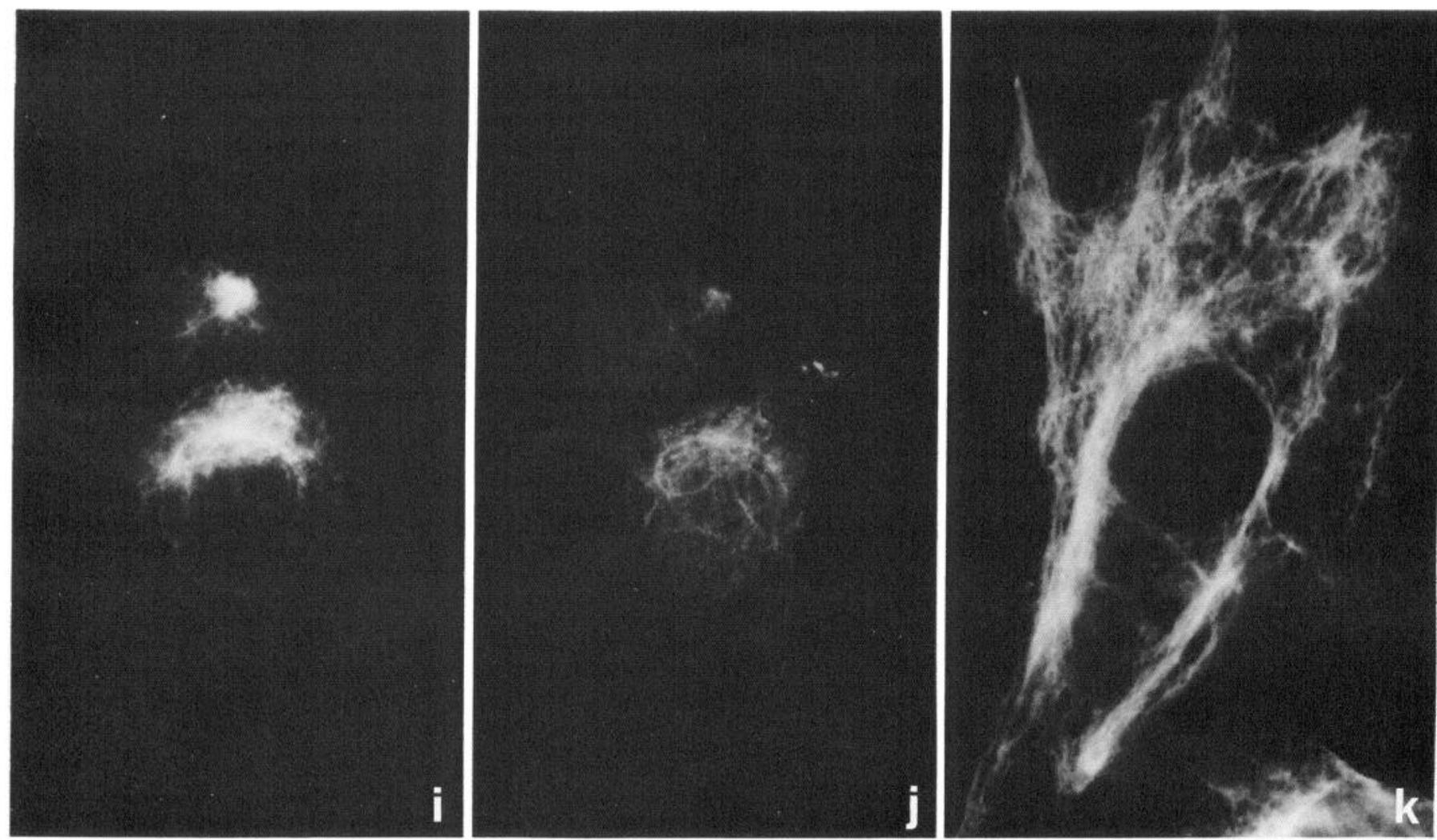

pattern are seen in PC12 cells labeled with $150 \mathrm{kDa}$ antibodies. PC12 vimentin ab-labeled filaments $(j)$ are distinct from $57 \mathrm{kDa}$ ab-labeled filaments (i). Vimentin antiserum shows a typical array of IF in BHK cells. $a-d, g, h, k$, Bar, $10 \mu \mathrm{m} . e, f, i, j$, Bar, $10 \mu \mathrm{m}$. 

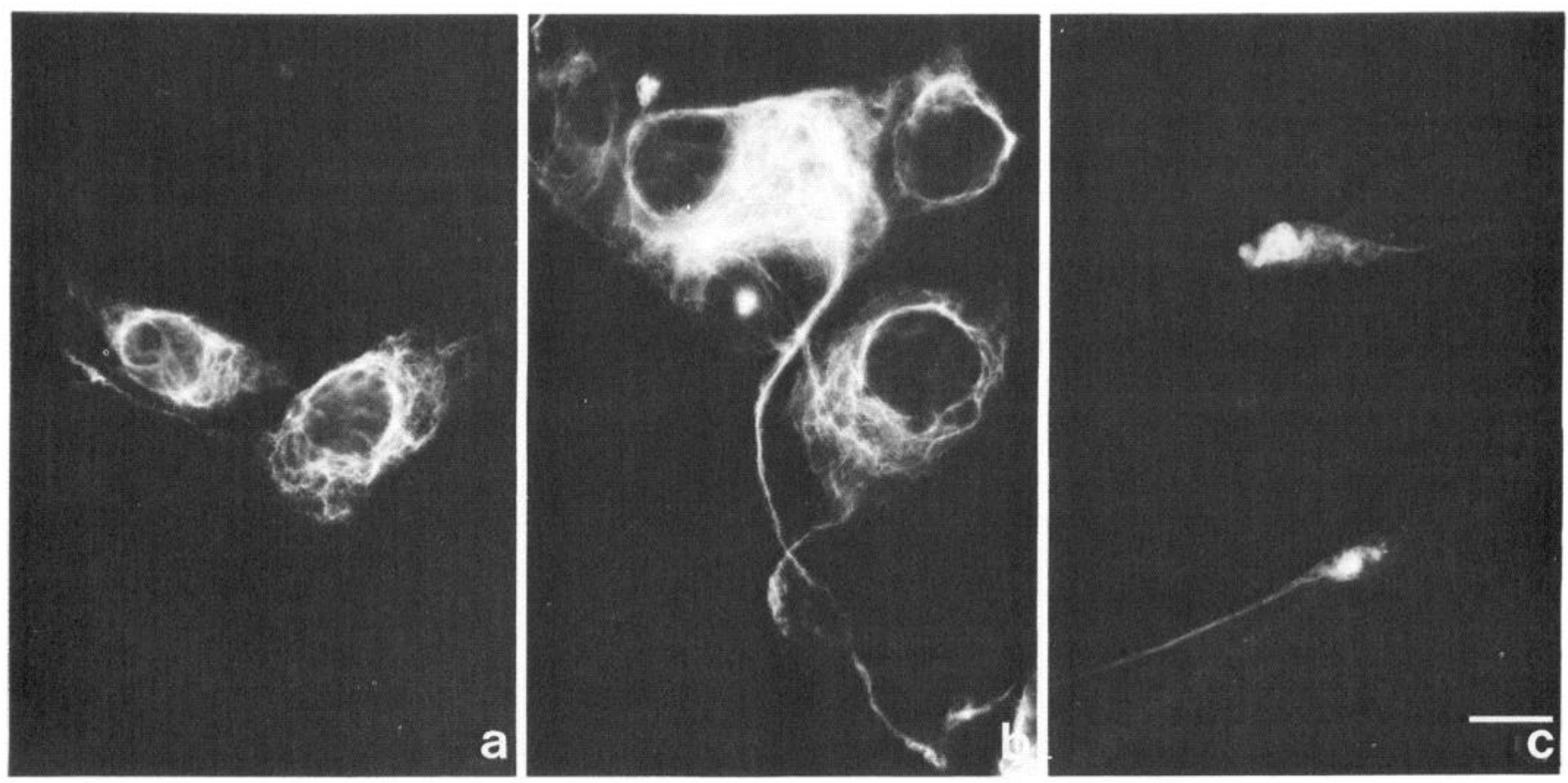

Figure 5. Immunofluorescence of NGF-treated PC12 cells. Cells labeled with a $57 \mathrm{kDa}$ ab $(a)$ or a $150 \mathrm{kDa}$ ab $(b, c)$ after $12 \mathrm{~d}$ of NGF treatment. The IF appear to be more dispersed throughout the cytoplasm $(a, b)$ than in untreated cells (see Fig. $4 b$ ). In addition, IF are often seen as a tortuous bundle in the neurite tip (c). Bar, $10 \mu \mathrm{m}$.

protein by its molecular weight. On the basis of our findings, we suggest that the PC12 $57 \mathrm{kDa}$ protein is an IF subunit that probably belongs to the neural IF group and has not yet been described in the literature.

The complexity of the IF polypeptide pattern in PC12 cells is reminiscent of the heterogeneity observed in the proteins that compose the HeLa cell IF. HeLa cells, a human epithelial cell type, contain IF proteins representative of more than one class of IF proteins - the keratin group and the vimentin class of structural subunits (Aynardi et al., 1984). Thus far, in the PC12 cell IF, we have identified NFT proteins in addition to the 57 $\mathrm{kDa}$ protein. We speculate that some of the remaining polypeptides may be keratinlike, not only because of the neuroepithelial origin of neurons, but because our preliminary observations indicate that some proteins in the $60-70 \mathrm{kDa}$ region blot with keratin antibodies. The $60-70 \mathrm{kDa}$ group of keratinlike proteins appears to be a consistent component of IF-enriched cytoskeletal preparations from many cell types (Aynardi et al., 1984; Zackroff et al., 1984; Goldman et al., 1986) and have been shown to be identical to the nuclear lamins (Goldman et al., 1986).

Our data regarding the immunofluorescence localization of NFT antibody-reactive proteins in PC12 cells is somewhat different from those previously reported. We find that the $150 \mathrm{kDa}$ NFT protein colocalizes with the $68 \mathrm{kDa}$ NFT protein in both untreated and NGF-treated cells, whereas Lee et al. (1982) and Lee and Page (1984) found a differential distribution of the 2 proteins. These 2 reports indicated that $150 \mathrm{kDa}$-positive fluorescence was found in stipples that lay over the nucleus or were perinuclear in location. To determine whether these stipples could be the same as the dots of fluorescence that appeared in the cytoplasm of $16 \%$ of the PC12 cells in our untreated cultures, we fixed and labeled unflattened PC12 cells with the monoclonal antibody to the 150 and $200 \mathrm{kDa}$ NFT proteins. We still found, even in our unflattened cell preparations, that the dots appeared to be distributed throughout the cytoplasm (L. M. Parysek and R. D. Goldman, unpublished observations) and were not specifically perinuclear, as Lee et al. (1982) and Lee and Page (1984) have described. Thus, the $150 \mathrm{kDa}$-positive stipples that we have identified here may not be the same as those previously reported, but may represent an intriguing packaged form of an IF subunit.

There are at least 2 possible explanations for the differences between our data and those obtained by Lee et al. (1982) and Lee and Page (1984). The most likely may be that our antibodies were of a different specificity than theirs. In addition to the difficulties inherent in attempting to compare immunologic data, it is possible that there are some differences between the cell lines being used in each of our laboratories. The PC1 2 cell line is characteristically very plastic (Guroff, 1985) and thus could account for most of the observed differences between this report and previous studies.

The apparent increase in the amount of isolatable IF-enriched cytoskeletal protein from PC12 cells after NGF treatment correlates with our immunofluorescence observations of an apparent increase in the mass of filamentous elements in NGFtreated cells. Not only does there seem to be an increase in the number of IF, but the distribution changes from primarily juxtanuclear to cytoplasmic and the IF extend throughout the neurites. An increase in observable IF in response to NGF treatment also has been shown in cultured sympathetic neurons by electron microscopy (Levi-Montalcini et al., 1968). Since NGF-treated PC12 cells are flatter and their size larger than untreated cells (Tischler and Greene, 1978), the appearance of greater numbers of IF might be expected. It is known that an IF distribution change occurs in cells when they change from a rounded state to a flattened, spread morphology (Goldman and Follett, 1970; Graham et al., 1974; Ross et al., 1975). These studies show that 

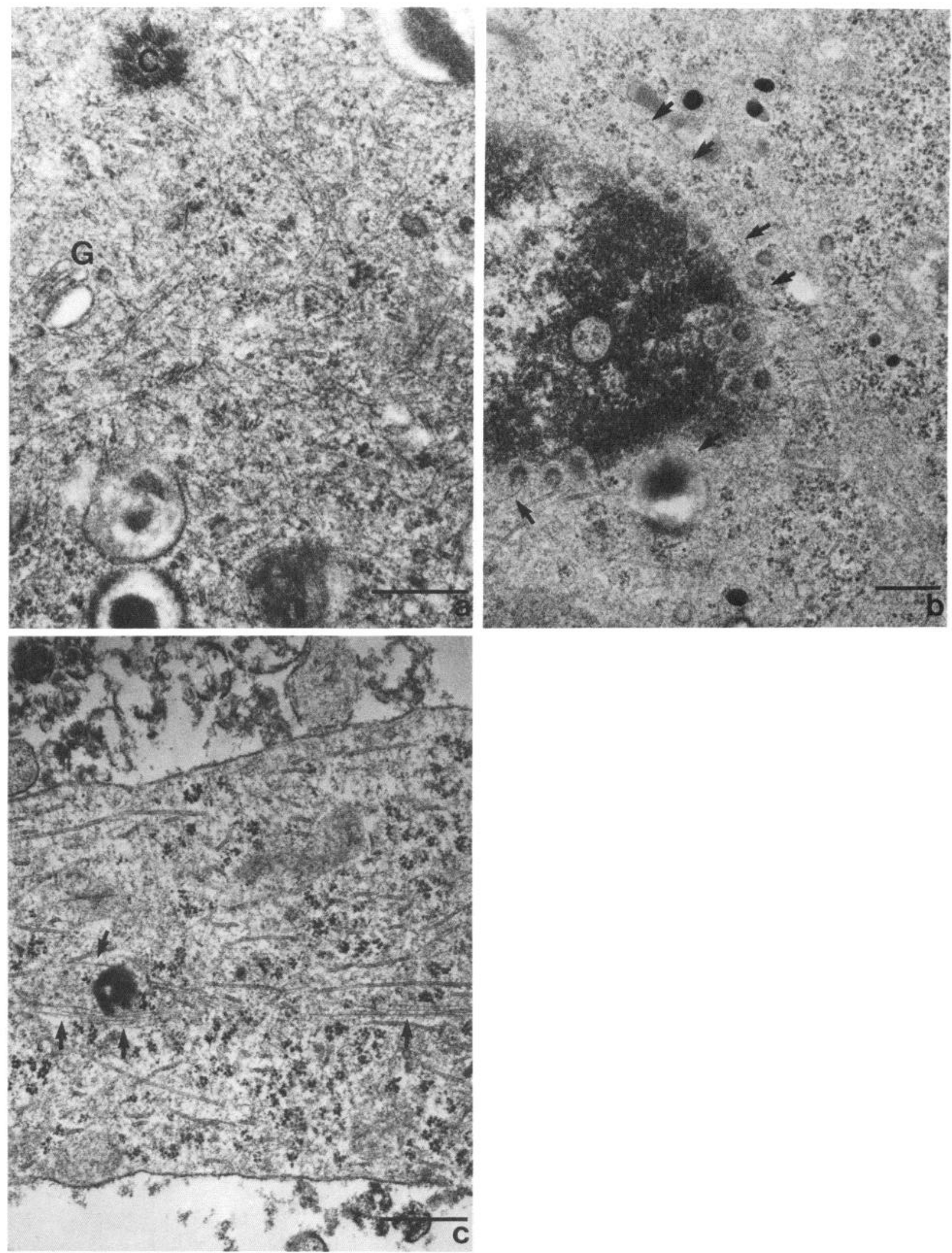

Figure 6. Electron microscopy of PC12 cells. Thin-sections of untreated $(a, b)$ or $7 \mathrm{~d}$ of NGF-treated $(c)$ PC12 cells. $a$, IF are most concentrated in the centriole $(C)$-Golgi $(G)$ region and $(b)$ just outside the nucleus in untreated cells. In addition to these 2 areas, individual IF and parallel arrays of can be detected throughout the cytoplasm of the NGF-treated cells (not shown) and in the neurites (c), where they tend to be centrally located within the neurite. Arrows indicate IF. Bar, $0.5 \mu \mathrm{m}$. 
IF are initially present as a perinuclear mass in rounded cells, but become dispersed throughout the cytoplasm of the flattened cell. Even though the morphologic changes induced in NGFtreated cells might give rise to the appearance of greater amounts of IF, the SDS-PAGE data support the idea that the increase is real.

The ELISA data on total cellular IF protein (insoluble and soluble) of Lee and Page (1984) appear to indicate that NGF induces the specific increase of immunodetectable NFT protein over vimentin. Our SDS-PAGE data on the PC12 cell IF cytoskeleton suggests that there is a relative increase in NFT proteins associated with the cytoskeleton over time, following NGF treatment. Our immunofluorescence data show that NFT proteins are present in the filamentous components of a greater number of PC1 2 cells treated with NGF than of untrcatcd cclls. Immunoblot analyses of the supernatants of the cytoskeletal preparations, however, do not appear to indicate that NGF promotes the movement of soluble IF proteins into the cytoskeleton (L. M. Parysek and R. D. Goldman, unpublished observations). It remains to be determined whether there is, in fact, specific synthesis of NFT proteins in preference to other IF proteins in response to NGF, or whether NGF enhances the immunodetectability of NFT proteins.

Although we cannot rule out the possibility that the NFT proteins compose filaments that are different from the $57 \mathrm{kDa}$ filaments, our data suggest that, in both untreated and NGFtreated cells, NFT proteins appear to be colocalized with filamentous elements containing the $57 \mathrm{kDa}$ IF protein. It is conceivable that the NFT subunits become associated with the 57 $\mathrm{kDa}$ filaments over the period of NGF treatment and, hence, the composition of the IF are altered. This would imply that there is a specific, NGF-induced function of IF in PC12 cells requiring an altered IF composition. The answers to questions posed by these possibilities may ultimately enable investigators to understand why IF are compositionally unique in different cell types.

\section{References}

Autilio-Gambetti, L., M. E. Velasco, J. Sipple, and P. Gambetti (1981) Immunochemical characterization of antisera to rat neurofilament subunits. J. Neurochem. 37: 1260-1265.

Aynardi, M. W., P. M. Steinert, and R. D. Goldman (1984) Human epithelial cell intermediate filaments: Isolation purification, and characterization. J. Cell Biol. 98: 1407-1421.

Bradford, M. (1976) A rapid and sensitive method for the quantitation of microgram quantities of protein utilizing the principle of proteindye binding. Anal. Biochem. 72: 248-254.

Cleveland, D. W., S. G. Fischer, M. W. Kirschner, and U. K. Laemmli (1977) Peptide mapping by limited proteolysis in sodium dodecyl sulfate and analysis by gel electrophoresis. J. Biol. Chem. 252: 11021106.

Feinstein, S. C., S. L. Dana, L. McConlogue, E. M. Shooter, and P. Coffino (1985) Nerve growth factor rapidly induces ornithine decarboxylase mRNA in PC12 rat pheochromocytoma cells. Proc. Natl. Acad. Sci. USA 82: 5761-5765.

Franke, W. W., E. Schmid, M. Osborn, and K. Weber (1978) Different intermediate-sized filaments distinguished by immunofluorescence microscopy. Proc. Natl. Acad. Sci. USA 75: 5034-5038.

Fukui, Y., S. Yumura, T. K. Yumura, and H. Mori (1986) Agaroverlay method: High resolution immunofluorescence for the study of the contractile apparatus. In Methods in Enzymology, R. B. Vallee, ed., pp. 573-580, Academic, New York.

Fukui, Y., S. Yumura, and T. K. Yumura (1987) Agar-overlay immunofluorescence: High resolution studies of cytoskeletal components and their changes during chemotaxis. In Methods in Cell Biology, J. A. Spudich and L. Wilson, eds., pp. 347-356, Academic, New York.
Goldman, A. E., G. Maul, P. M. Steinert, H.-Y. Yang, and R. D. Goldman (1986) The keratin-like proteins which coisolate with intermediate filaments of BHK-21 cells are nuclear lamins. Proc. Natl. Acad. Sci. USA 83: 3839-3843.

Goldman, R. D., and E. A. C. Follett (1970) Birefringent filamentous organelle in BHK-21 cells and its possible role in cell spreading and motility. Scicncc 169: 286-288.

Graham, D. I., N. K. Gonatas, and F. C. Charampous (1974) The undifferentiated and extended forms of $\mathrm{C} 1300$ murine neuroblastoma. Am. J. Pathol. 76: 285-312.

Granger, B. L., and E. Lazarides (1980) Synemin: A new high molecular weight protein associated with desmin and vimentin filaments in muscle. Cell 22: 727-738.

Greene, L. A., and A. S. Tischler (1976) Establishment of a monoadrenergic clonal line of rat adrenal pheochromocytoma cells which respond to nerve growth factor. Proc. Natl. Acad. Sci. USA 73: 2424 2428.

Guroff, G. (1985) PC12 cells as a model of neuronal differentiation. In Cell Culture in the Neurosciences, J. Bottenstein and G. Sato (eds.), pp. 245-272, Plenum Press, New York.

Hoffman, P. N., and R. J. Lasck (1975) The slow component of axonal transport. Identification of major structural polypeptides of the axon and their generality among mammalian neurons. J. Cell Biol. 66: 351-366.

Jones, J. C. R., and R. D. Goldman (1985) Intermediate filaments and the initiation of desmosome assembly. J. Cell Biol. 101: 506517.

Julien, J.-P., and W. E. Mushynski (1983) The distribution of phosphorylation sites among identified proteolytic fragments of mammalian neurofilaments. J. Biol. Chem. 258: 4019-4025.

Laemmli, U. K. (1970) Cleavage of structural proteins during the assembly of the head of phage T4. Nature 227:680-685.

Lee, V. M.-Y. (1985) Neurofilament protein abnormalities in $\mathrm{PC1} 2$ cells: Comparison with neurofilament proteins of normal cultured rat sympathetic neurons. J. Neurosci. 5: 3039-3046.

Lee, V. M.-Y., and C. Page (1984) The dynamics of nerve growth factor-induced neurofilament and vimentin expression and organization in PC12 cells. J. Neurosci. 4: 1705-1714.

Lee, V., J. Q. Trojanowski, and W. Schlaepfer (1982) Induction of neurofilament triplet proteins in PCl 2 cells by nerve growth factor. Brain Res. 238: 169-180.

Levi-Montalcini, R., F. Caramia, S. A. Luse, and P. U. Angeletti (1968) In vitro effects of the nerve growth factor on the fine structure of the sensory nerve cells. Brain Res. 8: 347-362.

Liem, R. K. H., and S. B. Hutchinson (1982) Purification of individual components of the neurofilament triplet: Filament assembly from the 70,000-dalton subunit. Biochemistry 21: 3221-3226.

Liem, R. K. H., S.-H. Yen, G. D. Salomon, and M. L. Shelanski (1978) Intermediate filaments in nervous tissues. J. Cell Biol. 79: 637-645.

Lieska, N., H.-Y. Yang, and R. D. Goldman (1985) Purification of the $300 \mathrm{~K}$ intermediate filament-associated protein and its in vitro recombination with intermediate filaments. J. Cell Biol. 101: 802813.

Oakley, B. R., D. R. Kirsch, and N. R. Morris (1980) A simplified ultrasensitive silver stain for detecting proteins in polyacrylamide gels. Anal. Biochem. 105: 361-363.

Olmsted, J. B. (1981) Affinity purification of antibodies from diazotized paper blots of heterogeneous protein samples. J. Biol. Chem. 256: 11955-11957.

Ross, J., J. B. Olmsted, and J. L. Rosenbaum (1975) The ultrastructure of mouse neuroblastoma cells in tissue culture. Tissue Cell 7: $107-136$.

Schlaepfer, W. W., and L. A. Freeman (1978) Neurofilament proteins of rat peripheral nerve and spinal cord. J. Cell Biol. 78: 653-662.

Starger, J. M., W. E. Brown, A. E. Goldman, and R. D. Goldman (1978) Biochemical and immunological analysis of rapidly purified $10 \mathrm{~nm}$ filaments from baby hamster kidney (BHK-21) cells. J. Cell Biol. 78: 93-109.

Steinert, P. M., J. C. R. Jones, and R. D. Goldman (1984) Intermediate filaments. J. Cell Biol. 99: 22s-27s.

Tischler, A. S., and L. A. Greene (1975) Nerve growth-factor-induced process formation by cultured rat pheochromocytoma cell. Nature 258: 341-342.

Tischler, A. S., and L. A. Greene (1978) Morphologic and cytochemical properties of a clonal line of rat adrenal pheochromocytoma cells which respond to nerve growth factor. Lab. Invest. 39: 77-89. 
Towbin, H., T. Staehlin, and J. Gordon (1979) Electrophoretic transfer of proteins from polyacrylamide gels to nitrocellulose sheets: Procedure and some applications. Proc. Natl. Acad. Sci. USA 76: 43504354.

Yang, H.-Y. N. Lieska, A. E. Goldman, and R. D. Goldman (1985) A 300,000-mol-wt intermediate filament-associated protein in baby hamster kidney (BHK-21) cells. J. Cell Biol. 100: 620-631.

Yumura, S., and Y. Fukui (1985) Reversible cyclic AMP-dependent change in distribution of myosin thick filaments in Dictyostelium. Nature 314: 194-196.

Yumura, S., H. Mori, and Y. Fukui (1984) Localization of actin and myosin for the study of amoboid movement in Dictyostelium using improved immunofluorescence. J. Cell Biol. 99: 894-899.

Zackroff, R. V., W. W. Idler, P. M. Steinert, and R. D. Goldman (1982) In vitro reconstitution of intermediate filaments from mammalian neurofilament triplet polypeptides. Proc. Natl. Acad. Sci. USA 79: 754-757.

Zackroff, R. V., A. E. Goldman, J. C. R. Jones, P. M. Steinert, and R. D. Goldman (1984) Isolation and characterization of keratin-like proteins from cultured cells with fibroblastic morphology. J. Cell Biol. 98: 1231-1237. 